EPiC Series in Computing
Volume 52, 2018, Pages 125-136
$\begin{aligned} & \text { ICT4S2018. 5th International Conference on Informa- } \\ & \text { tion and Communication Technology for Sustainability }\end{aligned}$

\title{
Innovation alliances for sustainable ICT Good practices and success factors, using the example of initiatives to improve the energy efficiency of data centers
}

\author{
Ralph Hintemann and Simon Hinterholzer \\ Borderstep Institute, Berlin, Germany \\ hintemann@borderstep.de, hinterholzer@borderstep.de
}

\begin{abstract}
Digitalization is driving the increasing energy and resource needs of ICT. In Germany, ICT accounts for eight percent of electricity consumption. Data centers alone currently consume $2.3 \%$ of the electricity in Germany, with an upward

trend.

Although the ICT sector is generally considered to be very innovative and new solutions are often implemented very quickly, deployment of energy- and resource-efficient innovations is frequently confronted with considerable obstacles and barriers.

Innovation alliances of companies are a promising instrument of governmental support for new environmental technologies in the fast-paced ICT sector. In the past ten years, several initiatives of this kind have been launched, e.g., the consortium GreenIT Amsterdam, the Innovationsallianz Rechenzentren (Innovation Alliance Data Centers) in Hesse, Germany, and the Netzwerk energieeffiziente Rechenzentren (Network EnergyEfficient Data Centers). Some of these initiatives have achieved remarkable successes.

The present paper analyzes such innovation alliances using the example of energy efficiency in data centers as the field of application. Three good-practice examples from Germany are presented. The paper shows what these innovation alliances can achieve and analyzes the factors contributing to their successful implementation. It concludes with concrete recommendations for practical implementation of such initiatives.
\end{abstract}

Index Terms-Innovation Alliances, GreenIT, Datacenter, Energy Efficiency, Sustainable ICT, Good Practices 


\section{Introduction}

\section{A. The challenge: Increasing resource consumption because of ICT}

At first glance, the connection appears logical. The more digital the worlds our lives and our work become, the more immaterial they are. The consequence: declining resource consumption. An e-mail replaces a letter, a video conference makes a business trip unnecessary. Intelligent traffic control systems help avoid detours, and traffic flows more smoothly. And modern digital devices are becoming "smarter" and smaller, and they use less and less energy. Ten years ago, we worked on PCs that used more energy than a modern refrigerator; today, we use highly efficient smartphones, tablets, or notebooks. And they consume less energy than an energy-saving light bulb.

But this appearance is deceptive. Although digitalization holds major potential for ecological transformation, it does not by any means herald a world with lower resource consumption automatically. Ecological successes certainly have been achieved in some areas, but at the same time, resource consumption in others has continued to increase despite or even because of the use of information and communication technologies (ICT) [1]. For example, energy consumption caused by the use of Internet is continuing to rise worldwide [2], the number of business trips in Germany is increasing despite growing numbers of telephone and video conferences [3] and the vision of a paperless office has not come true, either. In fact, paper consumption per capita in Germany has increased by $60 \%$ since 1980 [1].

Against this background, it can be stated that additional activities - especially on the part of the government - are required to ensure that the enormous resource efficiency potentials of ICT bring about a reduction of the absolute amount of resource consumption long-term [4].

\section{B. Energy consumption of data centers: Marked increase}

Like electricity supply and transportation routes, data centers have become essential infrastructure for business, public administration, and research. From 2003 to 2017, the IT floor space in German data centers increased by $67 \%$ to approx. 2 million $\mathrm{m}^{2}$; during the same period, energy consumption grew by more than $110 \%$ to approx. 12.8 billion $\mathrm{kWh}$ [5]. Despite enormous progress in IT technology, which enables ever-increasing and ever more energy-efficient processing power [6], growing energy consumption of data centers is assumed for the future as well. Projections assume that data centers in Germany will consume 16.4 billion $\mathrm{kWh}$ in 2025 [7], [8].

\section{Innovation alliances as an instrument of governmental support for increasing the energy efficiency of data centers}

Against the background of data centers' increasing energy consumption, numerous efforts exist in Germany and internationally to further boost their energy efficiency. They range from new legal frameworks such as the Ecodesign Implementing Measure for Entreprise Servers (product group Enterprise Servers - ENTR Lot 9 / Directive 2009/125/EC) to governmental support programs to increase the energy efficiency of data centers, for example the StepUp program in Germany [9], to innovation alliances such as GreenIT Amsterdam (www.greenitamsterdam.nl) or the Netzwerk energieeffiziente Rechenzentren (Network Energy-Efficient Data Centers). The latter will be examined more closely in this contribution.

In this context, an innovation alliance is defined as more than two organizations, at least one of which is a business, working together voluntarily with the explicit goal of generating or supporting innovations. If innovation alliances are used as an instrument of government policy, then this involves a state institution providing financial or other support to the collaboration.

Innovation alliances can be an attractive instrument of government policy to support energy and resource efficiency in ICT. Especially in this field, there are limits to what other measures such as legal 
regulations or financial support can achieve. Defining new technical standards or processing grant applications often takes more time than is available in this industry with its very rapid pace of innovation.

\section{Methodology}

Methodologically speaking, this project follows the action research approach in which researchers collaborate closely with the object of their research, namely the practitioners. The boundary between the researchers and those being researched is blurred [10], [11].

One important goal of action research is to further develop and change practices [10]. New solutions to problems can be developed because practice and theory are closely linked [12], [13].

The process of action research consists of the exploration, intervention, and evaluation phases. The exploration phase involves collecting data to gain knowledge about the existing problem. The intervention phase encompasses planning and then carrying out the action. Here, researchers observe and constantly reflect on the action. The purpose of the evaluation phase is to determine the impact of the action and which change it induced [10].

An important element of action research is a process-oriented perspective in which the researchers themselves participate in the process and change it [12].

In this concrete case, three innovation alliances for energy-efficient data centers are studied using the action research approach. The authors of this contribution were or are involved themselves and took the insights gained in the individual projects into account in the subsequent initiatives. The approaches taken in the innovation alliances are in part very different. Whereas the first innovation alliance presented is an initiative of the government of the German federal state of Hesse, the second is a cooperative research project, and the third a network initiated and established by small and medium-sized businesses and supported by the Federal Ministry of Economic Affairs and Energy.

The three innovation alliances and their goals are presented in individual sections below. The results achieved to date are outlined. Each section closes with lessons learned in the project.

Section VI summarizes the most important success factors for innovation alliances as well as the findings of an expert workshop on the topic that took place in Berlin on 15 May 2017. The participants were experts from the innovation alliances presented as well as other ones [14]. The paper ends with a conclusion.

\section{Good practice: Innovationsallianz Rechenzentren (Innova- tion Alliance Data Centers)}

\section{Overview of the initiative}

The idea for the Innovationsallianz Rechenzentren was developed in a study for the federal state of Hesse on the opportunities for reducing $\mathrm{CO}_{2}$ emissions through ICT solutions [15]. This was the first study to determine concrete figures on the structure of the data center landscape in Hesse and the amount of energy consumed by data centers there. DE-CIX, the world's leading Internet exchange with an actual peak traffic of more than six terabits per second [16], is located in this region. With approx. $40 \%$ of Germany's major data centers [15], Hesse has the highest concentration of data centers in Germany. Many suppliers of data centers and other businesses connected to the data center industry, such as major software manufacturers and firms offering total system-based solutions, as well as research institutes, are to be found in Hesse. 
Against this background, the idea emerged to bring the various actors and stakeholders together in a joint effort to increase the energy efficiency of data centers [15]. The Hessian Ministry of Economics took up this idea and commissioned the Borderstep Institute to support it in initiating an innovation alliance. The project Innovationsallianz Rechenzentren began in October 2014.

\section{E. Participants and goals}

A total of approx. 40 businesses (data centers, their suppliers and customers, software companies), research institutes, representatives of the state government, and the Aktionslinie Hessen-IT, economic development promoters, and representatives of individual municipalities in Hesse were involved in the Innovationsallianz Rechenzentren. The goals of the innovation alliance were to secure the strength of the region Frankfurt/Rhine-Main as a data center location into the future and to develop further innovations, with a particular focus on questions of energy consumption and energy efficiency. To this end, the strengths, weaknesses, opportunities, and threats of the data center location Hesse were determined in a SWOT analysis, on the basis of which measures were derived to retain the location's attractiveness. Within this framework, more and newer information on the data center market in Hesse was to be gathered jointly.

During the period in which Borderstep was commissioned with organizing the innovation alliance (10/2014 - 01/2016), two working groups were formed, and a total of three expert workshops and one conference were held. The main tasks of the Borderstep were the organization of these events, the management of the working groups and the scientific monitoring of the project.

\section{F. The most important results of the initiative}

Hesse as a data center location was assessed jointly on the basis of a SWOT analysis in the context of the innovation alliance. Innovation potentials for energy-efficient data centers were identified and discussed, and measures were decided on to further expand the strengths of the data center region Frankfurt/Rhine-Main and to respond to opportunities beneficial both to businesses and the environment. Numerous best-practice examples of energy-efficient data centers in Hesse were identified and documented.

The Innovationsallianz Rechenzentren provided important input for Hesse's digital strategy, in which data centers play a key role [17]. In addition, the project included a study on the data center market in Hesse [18], which produced important new insights:

- Data centers are very important to the economy. In Hesse alone, the data center industry employs approx. 35,000 people, and approx. 2 billion euros annually are invested in data centers.

- Hesse is the top location for data centers in Germany. In terms of IT floor space, almost onequarter of German data center capacity is installed in Hesse. In 2016, the investments in data centers in Hesse were approx. 10\% higher than in 2015.

- Data centers in Germany and Hesse are among the most energy-efficient ones worldwide.

Several initiatives for follow-on projects were developed in the context of the Innovationsallianz Rechenzentren (see Section V), for example the idea to establish the Netzwerk energieeffiziente Rechenzentren and a network of data center operators in Frankfurt. The government of the state of Hesse is currently preparing additional measures for increasing the energy efficiency of data centers in the context of its digital strategy.

\section{G. Lessons learned}

As this presentation of the results shows, the Innovationsallianz Rechenzentren achieved most of its goals. In particular, numerous new insights into the data center market and on the energy efficiency of 
the data centers in Hesse were gained. Collaboration in Hesse's digital strategy and anchoring the topic of data centers in this strategy created the basis for medium- to long-term strategic support for the energy efficiency of data centers in Hesse.

The goal of creating new innovations was not achieved directly. Although the initiative's public relations contributed to the discussion about new efficiency technologies, no concrete projects were derived from the initiative to date. Since the end of the commission for the Borderstep Institute in January 2016, the active exchange between members of the innovation alliance has practically come to a halt. During the relatively brief period of just 15 months, it was not possible to find a solution to continue the innovation alliance without additional financing from Hesse. Hardly any activities are taking place in the absence of an active driver. However, some follow-on activities have begun that can still achieve the goal of supporting innovation.

One challenge to the innovation alliance was the heterogeneous composition of its participants. While the small and medium-sized companies were mostly represented by decision makers, the major businesses were typically represented by staff at the operational level. Because of this constellation, the small and medium-sized companies in particular complained about the initiative's lacking effectiveness.

\section{Good practice: Project Total Energy Management for PRO- FESSIONAL DATA CENTERS (TEMPRO)}

\section{H. Overview of the initiative}

TEMPRO - Total Energy Management for Professional Data Centers - is a collaborative research project jointly initiated by Borderstep, seven further project partners, and three associated partners. It is supported through the 6th Energy Research Programme of the Federal Government. The project began in November 2016 and will continue through October 2019. New technical solutions were developed to significantly reduce the energy consumption of data centers. The focus is on a holistic approach to energy management. Instead of considering only energy consumption while the data center is in operation, as has usually been the case, the TEMPRO team viewed the entire life cycle of all devices and facilities in the data center-from production of raw materials to manufacturing and transportation to recycling.

\section{Participants and goals}

Besides the Borderstep Institute and two universities, five companies are involved in the project, two of them data center operators, two companies providing planning and consulting services, and one recycling company (for details, see https://tempro.uni-oldenburg.de/).

The project has two main goals:

- to create a basis for assessing energy and resource efficiency of data centers holistically, and

- to research new efficiency technologies in data centers resulting in major energy savings.

In other words, TEMPRO is doing more than just developing the scientific basis for a holistic view of energy management. At the same time, software tools are being developed in the project that enable holistic evaluation of a data center's energy efficiency, and technical solutions are being researched and tested that contribute to reducing energy consumption overall. 


\section{J. The most important results of the initiative}

Final results are not yet available since the TEMPRO project is still ongoing and has not even reached its halfway point. Nonetheless, a number of preliminary findings have emerged, the most important of which are briefly outlined in the following.

The current energy consumption of data centers in Germany during operations was determined using a model covering the various components of a data center in product groups. The model was developed at the Borderstep Institute [19]. Figure 1 shows the energy consumption of servers and data centers in Germany, as calculated with the model, broken down according to the various categories of devices.

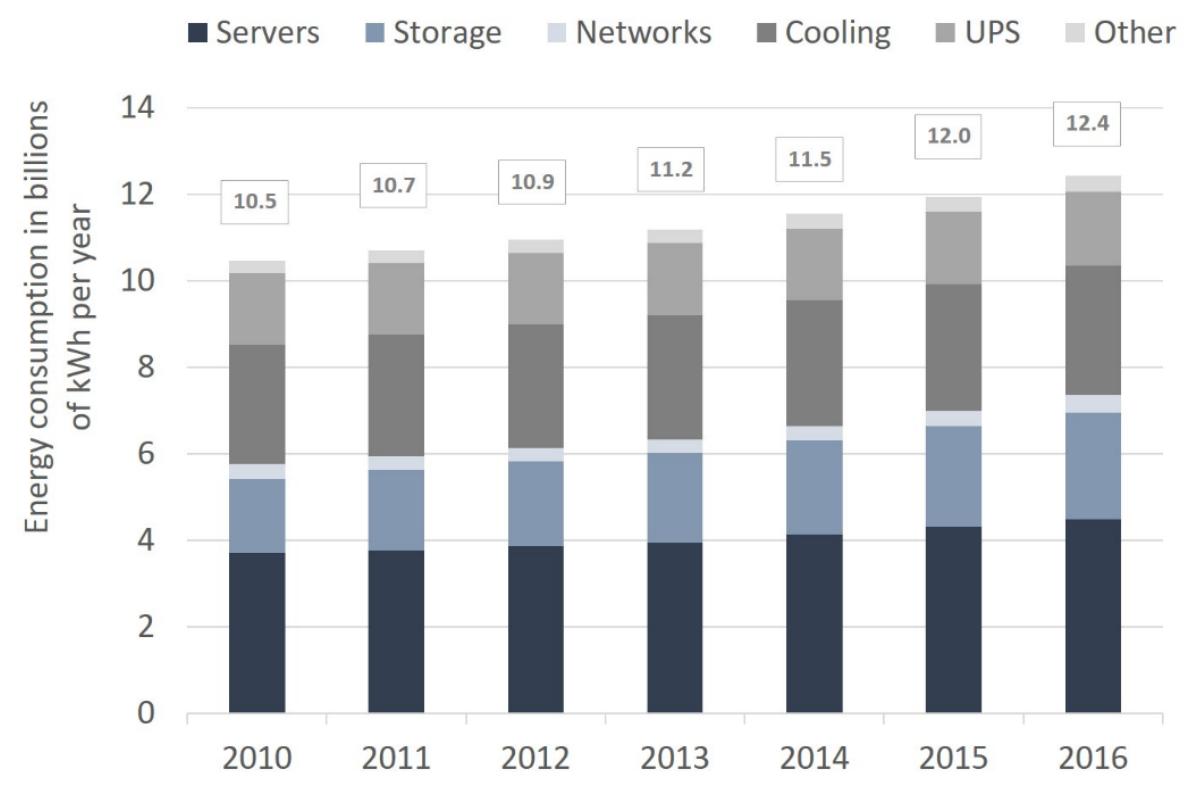

Fig. 1. Energy consumption of servers and data centers in Germany from 2010 to 2016 (source: [20])

The energy consumption of manufacturing, transportation, and disposal of the components of a data center are currently being determined on the basis of the model. It is also being used for analyzing the materials present in data centers.

A further interim finding is an analysis of the most important current and future technologies that can be used in data centers to improve holistic energy efficiency. It involved preparing innovation radars for the three technology fields cooling, electricity supply, and IT hardware and management. Figure 2 shows an example of an innovation radar for the technology field cooling. The technology radars depict new technologies on the market transparently, thus supporting their dissemination. 


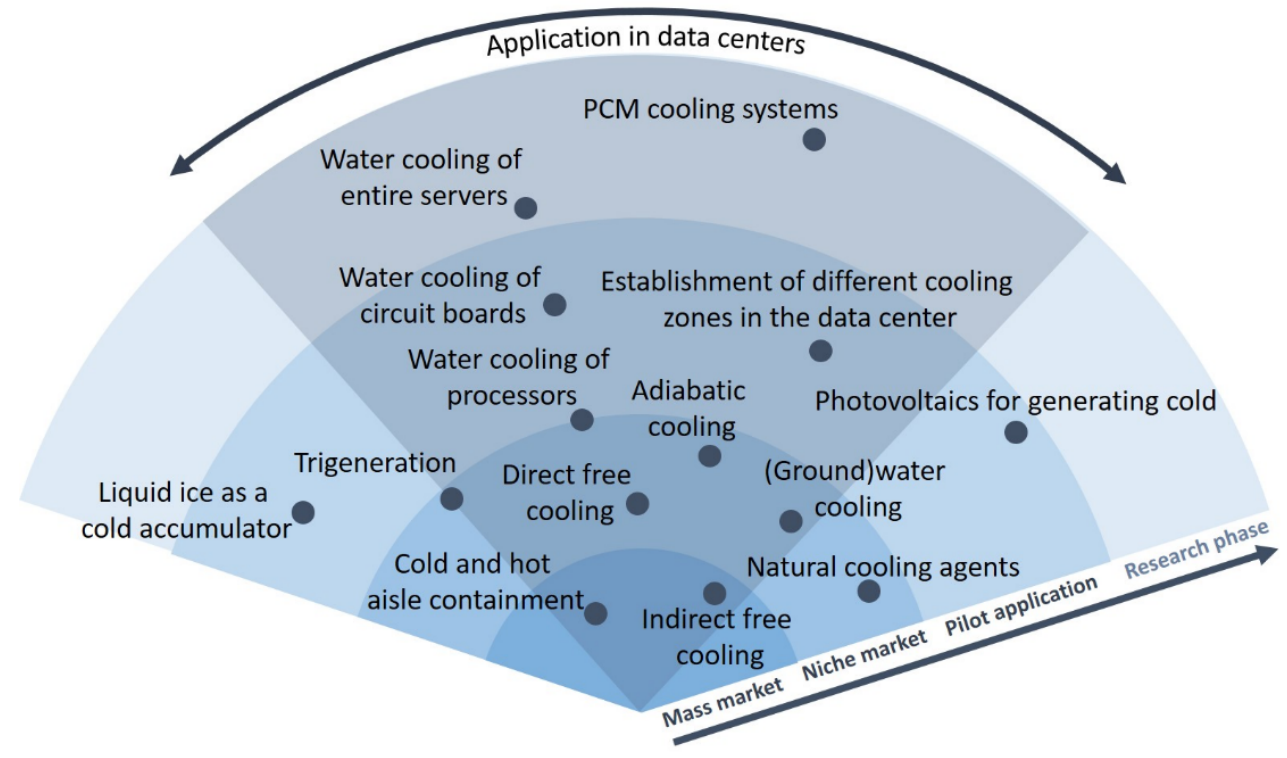

Fig. 2. Technology radar for cooling

In addition, a web tool is currently being developed in TEMPRO that helps data center operators estimate energy efficiency of their data centers holistically. TEMPRO will also provide research findings as input for the standardization efforts concerning suitable indicators for the energy and resource efficiency of data centers.

\section{K. Lessons learned}

One important insight from TEMPRO's first year is, that it is very positive for the work of innovation alliances if at least some of the partners already know each other from earlier collaborations. This significantly increases the speed and effectiveness with which findings are achieved in such projects.

A balanced combination of research that can quickly result in concrete new solutions and business models for the partners on the one hand and research that supports market transparency, but does not promise proceeds for the partners in the short term, on the other can have positive effects on the overall findings.

Another finding is that positive collaboration experiences can sometimes lead to project partners very quickly beginning to work together outside the initiative as well.

\section{Good practice: Netzwerk energieeffiziente Rechenzentren}

\section{Overview of the initiative}

The Netzwerk energieeffiziente Rechenzentren — NeRZ (www.ne-rz.de) - is a network of small and medium-sized technology companies in the data center industry in Germany. It is supported through the Central Innovation Programme for SMEs (ZIM) of the Federal Ministry for Economic Affairs and Energy. The goal of supporting this network is to promote collaboration of small and medium-sized com- 
panies in innovation, thereby providing support to the companies' innovation capacity and competitiveness long-term [21]. NeRZ began in March 2017. Support has been granted initially through February 2018 and may be extended through 2020.

The NeRZ initiative grew out of the Innovationsallianz Rechenzentren. However, since NeRZ is not limited to Hesse, most of its members were new to the network.

\section{Participants and goals}

Eight small and medium-sized companies are involved in NeRZ (for details, see http://nerz.de/ueber-uns/), ranging from startups to businesses already active in the market for decades. When the members of NeRZ were selected, care was taken to ensure it would not include direct competitors.

The goals of NeRZ are to engage in joint public relations and to work together to develop new energy efficiency solutions for data centers. The network seeks to anchor the economic and societal importance of data centers and their energy efficiency more firmly in the awareness of politicians and the general public. Network participants jointly develop project ideas for new energy-efficient solutions which are to be put into practice by bilateral or multilateral partnerships within the network. In some cases, the partners seek to obtain public research funding for the projects.

\section{N. The most important results of the initiative}

A number of results have already been achieved in the first eight months of the initiative. A project website was launched, a corporate design for presenting the network to the public was developed, and a study on the current development of the data center market and the energy efficiency of data centers in Germany was prepared. The study also involved a survey of 300 data center operators. This covers approx. one-quarter of the total market in Germany, measured in terms of IT floor space. For example, the study sheds light on the measures taken in data centers to increase energy efficiency (Fig. 3). The dominant measures concern cooling and climate control of the data centers and the servers. These areas are also considered to hold the highest potentials for savings in the future [22].

\section{At which points were you able to save energy or reduce carbon dioxide emissions in recent years?}

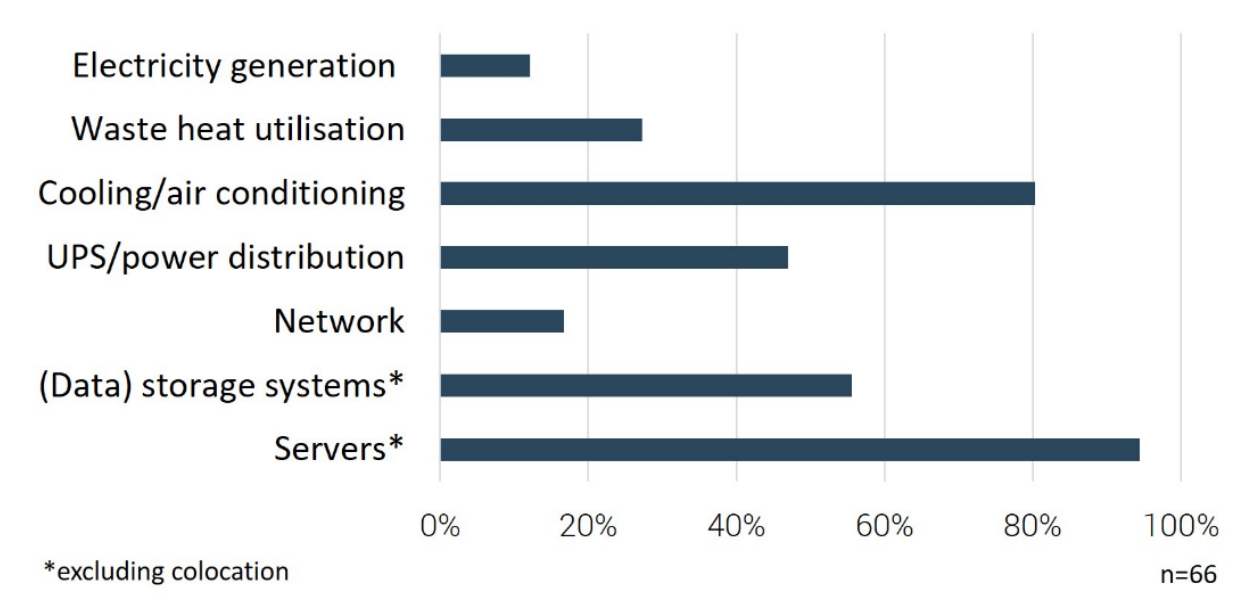

Fig. 3. Measures already taken to improve energy efficiency-Findings from a survey of data center operators in 2017 (source: [22]) 
The study also provides important findings on the competitive situation of data centers in Germany compared with other countries, for example how the data center operators assessed various location factors (Fig. 4). Germany as a business location benefits from the fact that all of the location factors considered most important - namely reliable electricity supply, connection to Internet nodes, data protection, and legal certainty - were considered to be very good in Germany, compared with other countries. Significant weaknesses of Germany as a business location are seen in the relatively long permitting procedures for data centers and the high electricity prices. There is a levy on electricity prices in Germany6.79 euro cents per $\mathrm{kWh}$ in 2018 - because of subsidies for renewable energy sources. Combined with the other levies on the price of electricity, this means that data centers in Germany pay 15 euro cents per $\mathrm{kWh}$ or more. For comparison: prices are now just under 4 euro cents per $\mathrm{kWh}$ in Sweden. On the one hand, the high electricity prices mean that energy efficiency technologies pay for themselves more quickly in Germany than in other countries, but also that major mega- or hyperscale data centers are typically built outside Germany [22].

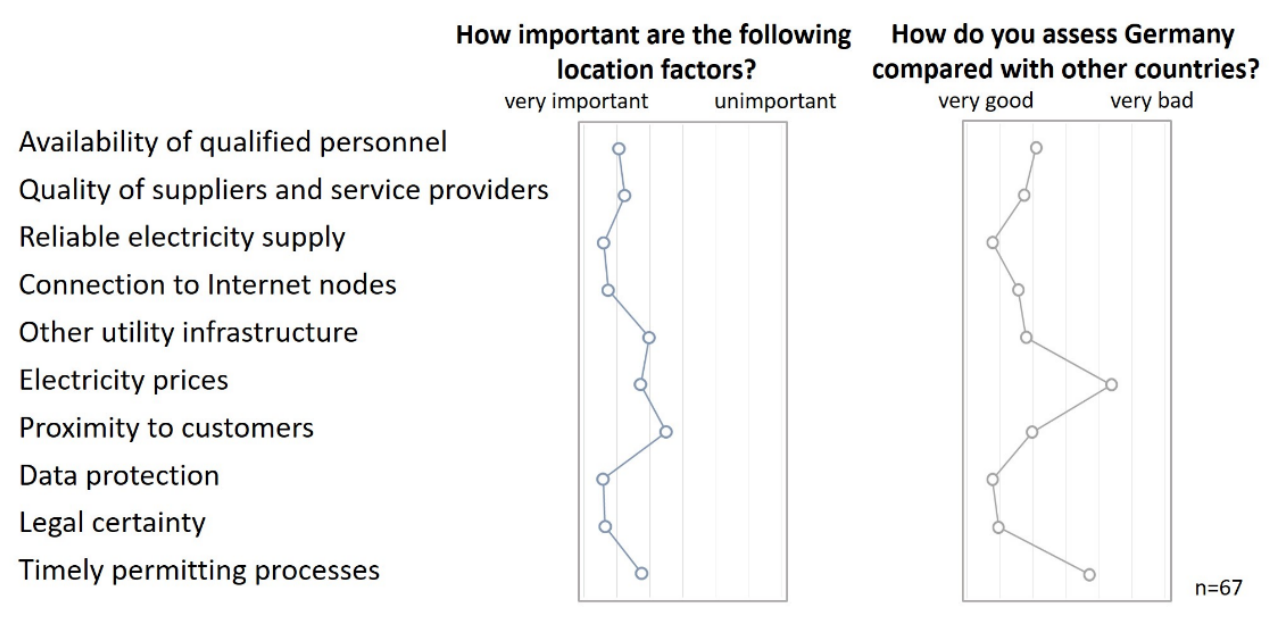

Fig. 4. Assessment of location factors for data centers in Germany-Findings from a survey of data center operators in 2017 (source: [22])

German media reported extensively about the establishment of NeRZ and the findings of the study, so the goal of joint public relations was achieved.

Project outlines for four bilateral or multilateral research projects that are to develop energy efficiency innovations for data centers in the coming years have already been prepared within NeRZ.

\section{O. Lessons learned}

One important insight from the work conducted to date in NeRZ is that an innovation alliance can work very quickly and effectively if all of its members are at the executive level. As a rule, they can reach decisions and make resources available very rapidly.

The fact that some members already had very good personal contact with each other even before the network was established and that new members were integrated very quickly had very positive impacts on the type and the efficiency of collaboration. 
However, such intensive collaboration also requires considerable time and effort for communication. At times, defining common projects required weekly conference calls and multiple personal meetings per month.

This proved to be a challenge for integrating startups in the network. In particular the two startups involved are so busy establishing their own businesses that they cannot participate regularly in such communication.

\section{Success factors for innovation alliances of energy-efficient data centers}

The innovation alliances discussed in this paper were presented at an expert workshop in Berlin in May 2017 along with other similar initiatives, such as GreenIT Amsterdam, the initiative GreenIT-BB (www.greenit-bb.de/), and the GreenIT Allianz Deutschland (GreenIT Alliance Germany). Three key success factors for innovation alliances in the field of green computing were identified in the lectures and a panel discussion:

As a rule, successful innovation alliances need public funding in their initial phase.

A key success factor for innovation alliances is the actors' commitment. In every successful innovation alliance, it is possible to identify specific individuals who were involved in initiating it and are decisive for its success.

Suitable business models for the innovation alliances are needed to establish them long-term. Ideally, they support both the members' and the alliances' activities and the financing of such activities.

\section{Summary of the experiences with innovation alliances for energy-efficient data centers}

In summary, innovation alliances are a very useful government instrument for promoting energy efficiency, especially in the fast-paced ICT sector. As shown above, such alliances can produce results that would not have been possible without public funding. In the states or regions where such innovation alliances are established, the market structures and the directions of technical developments are significantly more transparent than elsewhere. That is shown by the example of GreenIT Amsterdam and the initiatives from Germany presented here. This transparency is promoted above all through the close and trust-based collaboration between researchers and businesses in such innovation alliances.

Some important success factors for establishing successful innovation alliances were described in the previous section; they range from public funding in the initial phase to the great significance of personal commitment to the necessity of suitable business models for establishing innovation alliances long-term.

In addition, four insights can be gained from the analysis of the good-practice examples:

- It is very advantageous if the networks are managed by experienced project managers who know the industry well.

- The members' own motivation to cooperate in innovation alliances is decisive. Members who join simply "to be a part of it" or who were urged to get involved generally do not contribute input actively.

- The members of innovation alliances should be neither too homogeneous nor too heterogeneous. Negative impacts must be expected if members are close competitors. Collaboration between 
multiple major corporations and multiple small or medium-sized businesses often proves difficult because of the different decision-making structures.

- The involvement of state institutions in an innovation alliance can promote its members' motivation to participate and actively work in an innovation alliance. This is true above all for major corporations; state involvement is not as important for small and medium-sized businesses.

In order to further increase the efficiency and effectiveness of innovation alliances in the field of green computing and to generalize and exchange the insights gained through managing the alliances even more, it is advisable to internationalize the experiences and results and also to network the innovation alliances internationally as well. An initial joint workshop on the topic was held in Berlin in May 2017. Discussion of the topic during the ICT4S conference can be a further milestone toward more innovation alliances to promote sustainable ICT use.

\section{Acknowledgments}

The present contribution is based on the insights from the projects Innovationsallianz Rechenzentren, TEMPRO, and NeRZ. We thank all the project partners for their collaboration, which was always very constructive and enjoyable, and for the broad support toward reaching the projects' goals.

\section{References}

[1] R. Hintemann, 'Software, Internet, Computer - noch lange nicht »green«', in Wirtschaft im ZukunftsCheck: So gelingt die Grüne Transformation, München: Oekom, 2017.

[2] R. Hintemann and J. Clausen, 'Green Cloud? The current and future development of energy consumption by data centers, networks and end-user devices', in Proceedings of ICT for Sustainability 2016, Amsterdam, The Netherlands, 2016 [Online]. Available: http://www.atlantispress.com/php/pub.php?publication=ict4s-16. [Accessed: 05-Sep-2016]

[3] VDR, 'VDR-Geschäftsreiseanalyse 2015', Frankfurt, 2015 [Online]. Available: https://www.vdrservice.de/fileadmin/der-verband/fachmedien/geschaeftsreiseanalyse/VDR-

Geschaeftsreiseanalyse_2015.pdf. [Accessed: 02-Jun-2016]

[4] K. Fichter, R. Hintemann, S. Beucker, and S. Behrendt, 'Gutachten zum Thema „Green IT - Nachhaltigkeit“ für die Enquete-Kommission Internet und digitale Gesellschaft des Deutschen Bundestages', Borderstep Institut für Innovation und Nachhaltigkeit, Institut für Zukunftsstudien und Technologiebewertung (IZT), Berlin, Gutachten Ausschussdrucksache 17(24)058, 2012 [Online]. Available: http://www.bmwi.de/Dateien/Green-IT/PDF/green-it-nachhaltigkeit-enquete-kommissioninternet-und-digitale-gesellschaft,property $=$ pdf,bereich=green-it,sprache=de,rwb=true.pdf

[5] R. Hintemann, 'Boom der Rechenzentren in Deutschland - mehr Investitionen, steigender Energiebedarf', Borderstep Institut für Innovation und Nachhaltigkeit, Berlin, 2018.

[6] J. G. Koomey, S. Berard, M. Sanchez, and H. Wong, 'Implications of historical trends in the electrical efficiency of computing', Ann. Hist. Comput. IEEE, vol. 33, no. 3, pp. 46-54, 2011.

[7] L. Stobbe, R. Hintemann, M. Proske, J. Clausen, H. Zedel, and S. Beucker, 'Entwicklung des IKTbedingten Strombedarfs in Deutschland - Studie im Auftrag des Bundesministeriums für Wirtschaft und Energie', Fraunhofer IZM und Borderstep Institut, Berlin, 2015 [Online]. Available: http://www.bmwi.de/BMWi/Redaktion/PDF/E/entwicklung-des-ikt-bedingten-strombedarfs-indeutschland-abschlussbericht, property $=$ pdf,bereich=bmwi2012,sprache=de,rwb=true.pdf

[8] R. Hintemann, S. Beucker, J. Clausen, L. Stobbe, M. Proske, and N. F. Nissen, 'Energy efficiency of data centers - A system-oriented analysis of current development trends', in EGG 2016+ Proceedings, Berlin, 2016.

[9] Bundesanzeiger, 'Dritte Bekanntmachung zur Richtlinie für die Förderung von Stromeinsparungen im Rahmen wettbewerblicher Ausschreibungen: Stromeffizienzpotentiale nutzen - STEP up!', Feb. 2017 
[Online]. Available: https://stepup-energieeffizienz.de/dateien/teilnehmen/archiv/3-

foerderbekanntmachung-step-up-abgelaufen.pdf. [Accessed: 20-Oct-2017]

[10] E. Zojer, E. Faul, and H. Mayer, 'Aktionsforschung_,Be part of it “", ProCare, vol. 18, no. 9, pp. 12-16, 2013.

[11] C. Perry and E. Gummesson, 'Action research in marketing', Eur. J. Mark., vol. 38, no. 3/4, pp. 310-320, 2004.

[12] H. Von Unger, M. Block, and M. T. Wright, 'Aktionsforschung im deutschsprachigen Raum: zur Geschichte und Aktualität eines kontroversen Ansatzes aus Public Health Sicht', Wissenschaftszentrum Berlin für Sozialforschung gGmbH (WZB), Berlin, 303, 2007.

[13] K. Lewin, 'Action research and minority problems', J. Soc. Issues, vol. 2, no. 4, pp. 34 46, 1946.

[14] Borderstep Institut, 'Innovationsallianzen Green Computing - Fachforum 3, Borderstep Impact Forum 2017', 15-May-2017. [Online]. Available: https://www.borderstep.de/event/fachforuminnovationsallianzen-green-computing/. [Accessed: 10-Oct-2017]

[15] J. Clausen, S. Beucker, and R. Hintemann, 'CO2-Einsparung durch IKT und in der IKT in Hessen Entwicklungspotenziale und Handlungsoptionen Studie im Auftrag der Aktionslinie Hessen-IT', Berlin, 2014 [Online]. Available: www.hessen-it.de/mm/mm001/CO2_Final.pdf. [Accessed: 10-May-2014]

[16] DE-CIX, 'About DE-CIX - Where all networks meet', 2018. [Online]. Available: https://www.decix.net/about/. [Accessed: 07-Mar-2018]

[17] HMWEVL (Hrsg.), 'Strategie Digitales Hessen Intelligent. Vernetzt. Für Alle', Hessisches Ministerium für Wirtschaft,Energie, Verkehr und Landesentwicklung (HMWEVL), Wiesbaden, 2016 [Online]. Available: https://www.digitalstrategie-hessen.de/img/Digitalstrategie_Hessen_2016_ver1.pdf. [Accessed: 15-Jun-2016]

[18] R. Hintemann and J. Clausen, 'Der Rechenzentrumsmarkt in Hessen - Aktueller Stand im Jahr 2015 und Ausblick', Borderstep Institut für Innovation und Nachhaltigkeit, Berlin, 2016 [Online]. Available: http://www.borderstep.de/wp-content/uploads/2016/01/Studie-Rechenzentren-in-Hessen-2015-Stand-1301-2016.pdf

[19] K. Fichter and R. Hintemann, 'Beyond Energy. The Quantities of Materials Present in the Equipment of Data Centers', J. Ind. Ecol., vol. 18, no. 6, pp. 846-858, 2014.

[20] R. Hintemann, 'Trotz verbesserter Energieeffizienz steigt der Energiebedarf der deutschen Rechenzentren im Jahr 2016.', Borderstep Institut für Innovation und Nachhaltigkeit, Berlin, 2017 [Online]. Available: https://www.borderstep.de/wp-content/uploads/2017/03/Borderstep_Rechenzentren_2016.pdf

[21] BMWi (Hrsg.), 'Boosting Innovation: Central Innovation Programme for SMEs', Federal Ministry for Economic Affairs and Energy (BMWi), Berlin, 2015 [Online]. Available: https://www.zimbmwi.de/download/infomaterial/zim-brochure-en. [Accessed: 10-Nov-2017]

[22] R. Hintemann, 'Energieeffizienz und Rechenzentren in Deutschland - weltweit führend oder längst abgehängt?', Netzwerk energieeffiziente Rechenzentren - NeRZ, Berlin, 2017 [Online]. Available: https://www.borderstep.de/wp-content/uploads/2017/07/NeRZ-Studie-Rechenzentrumsmarkt-30-062017.pdf. [Accessed: 25-Oct-2017] 